\title{
LETRAMENTO E EMPODERAMENTO FEMININO NA ASSOCIAÇÃO DE MULHERES RURAIS DE SAQUINHO
}

\author{
Aurea da Silva Pereira ${ }^{1}$ \\ Elaine de Araújo Carneiro ${ }^{2}$
}

\section{Resumo}

O presente artigo apresenta o recorte da pesquisa construída no subprojeto de pesquisa intitulado "Letramento e empoderamento feminino: Impactos do letramento na atuação social e política das participantes da Associação de Mulheres Rurais de Saquinho, no município de Inhambupe-BA"3. Pretendemos, neste texto, apresentar e discutir a importância das práticas de letramentos utilizadas pelas mulheres da Associação de Mulheres Rurais de Saquinho e Região. No processo de construção dos dados e análise do estudo foi preciso conhecer e analisar as práticas de letramento utilizadas e produzidas na associação com o objetivo de compreender de que forma essas práticas podem contribuir para o empoderamento feminino. A pesquisa é de base qualitativa com ênfase ao método (auto)biográfico e entrevista narrativa. Para conhecer o percurso da AMRS (Associação de Mulheres Rurais de Saquinho), realizamos uma entrevista narrativa com Dona Sônia, atual presidenta da associação e roda de conversas interativas com as mulheres associadas, além da observação participante nos eventos, e registramos todas atividades sociais e culturais organizadas pela associação, atentandonos ao foco da pesquisa. Observamos que a AMRS se constitui para as mulheres e comunidade como uma agência de letramento e um espaço de empoderamento feminino. No processo de interação entre as mulheres, elas produzem documentos, participam de palestras, seminários e movimentos sociais organizados por elas. Tudo isso fomenta discussões sobre a formação social e política de mulheres rurais e suas possibilidades de ascensão e visibilidade instrumentalizadas pelas práticas de letramento. Os resultados da pesquisa apontam a presença de lideranças femininas na comunidade, nas atividades da igreja e nos movimentos sociais, especificamente, a presença e participação marcante na Associação das Mulheres; por outro lado, observamos a necessidade de um estudo sobre as relações de gênero no tocante aos papeis que a figura masculina exerce no âmbito dos movimentos sociais e nos espaços da Associação de agricultores da comunidade.

\footnotetext{
1 Doutora em Educação pela Universidade do Estado da Bahia (PPGEduC-UNEB). Professora permanente do Programa de Pós-graduação em Crítica Cultural (UNEB). E-mail: aureauneb@ gmail.com.

2 Graduada em Letras Vernáculas, Licenciatura em Língua Portuguesa e Literaturas de Língua Portuguesa. Foi bolsista de Iniciação Científica CNPq - CAPES. E-mail: elaineacarneiro@ hotmail.com.

${ }^{3}$ Este subprojeto está vinculado ao Projeto de Pesquisa Letramentos em Comunidades Rurais: Impactos Sociais na Família, Escola e Comunidades adjacentes ao município de Alagoinhas-BA. O referido projeto teve início de 2015-2021.
} 
Palavras-chave: Letramentos. Mulheres. Empoderamento.

\title{
LITERACY AND FEMALE EMPOWERMENT IN THE ASSOCIATION OF RURAL WOMEN OF SAQUINO (BA)
}

\begin{abstract}
This article presents the results of a research on social literacy and the process of social and political action of women participating in the Association of Rural Women of the Saquinho rural community, in the municipality of Inhambupe-Ba. In the process of data gathering and analysis, it became necessary to examine the literacy practices used and produced in the association in order to understand how these practices may contribute to female empowerment. The research is qualitative in nature, based on autobiography and narrative interviews. A narrative interview was conducted with Dona Sônia, current president of the association as well as rounds of interactive talks with the women in the association. We also registered all social and cultural events organized by the association. We observed that the association functions for the community women as a literacy agency and a space for emancipation strategies. The analyses took into account the impact of the literate practices used in the Association of Rural Women of the community, and this fomented discussions about the formation of community associations of rural women and their possibilities of ascension and visibility instrumented by literacy practices. The research results indicate the growing presence of women leaders, in church activities and social movements of the community, specially a significant participation in the Association of Women; we also observed the need for a study on gender relations with regard to the roles played by the male figure within the social movements and the community farmers association.
\end{abstract}

Keywords: Literacy. Women. Social impacts.

\section{LITERACÍA Y EMPODERAMIENTO FEMENINO EN LA ASOCIACIÓN DE MUJERES RURALES DE SAQUINHO}

\section{Resumen}

El presente artículo presenta un recorte de la investigación construida en el proyecto de pesquisa intitulado "Literacía y empoderamiento femenino: impactos de la literacía en la actuación social y política de las participantes de la Asociación de Mujeres Rurales de Saquinho, en municipio de Inhambupe-BA". Pretendemos, en esto texto, presentar y discutir la importancia de las prácticas de literacía utilizadas por las mujeres de la Asociación de Mujeres Rurales de Saquinho y regiones. En el proceso de construcción de los datos y anàlises del estudio fue preciso conocer y analizar las prácticas de literacía utilizadas y producidas en la asociación con el objetivo de comprender de que maneras esas prácticas pueden contribuir para el empoderamiento femenino. La búsqueda es de base cualitativa con énfasis en el método (auto)biográfico y entrevistas narrativas. Para conocer el camino da AMRS (Asociación de Mujeres Rurales de Saquinho), realizamos una entrevista narrativa con Doña Sônia (actual presidente de la 
asociación) y ruedas de conversas interactivas con las mujeres asociadas; además de las observaciones participantes en los eventos, registramos todas las actividades sociales y culturales organizadas por la asociación. Observamos que la AMRS se constituye para las mujeres y la comunidad como una agencia de literacía y un espacio de empoderamiento femenino. En el proceso de interacción entre las mujeres, ellas producen documentos, participan de las conferencias, seminarios y movimientos sociales que organizan. Todo eso fomenta discusiones sobre la formación social y política de las mujeres rurales y sus posibilidades de elevación social y visibilidad instrumentalizadas por las prácticas de literacía. Los resultados de la investigación apuntan para la presencia de líderes femeninas en las comunidades, en las actividades de iglesia y en los movimientos sociales de la comunidad, particularmente, la presencia y participación sobresaliente en la Asociación de las Mujeres; así observamos también la necesidad de un estudio sobre las relaciones de géneros cuanto a los papeles que la figura masculina tiene en el ámbito de los movimientos sociales y en los espacios de la Asociación de Agricultores de la comunidad.

Palabras clave: Letramento. Mujeres. Empoderamiento.

\section{Considerações preliminares: contexto e aspectos metodológicos pesquisa}

O presente trabalho, desenvolvido na comunidade rural de Saquinho, município de Inhambupe (BA), tendo como foco os impactos do letramento na atuação social e política das participantes da Associação de Mulheres Rurais de Saquinho integra-se aos estudos etnográficos de letramento em comunidades rurais ${ }^{4}$. Antes da definição da associação de mulheres como lócus da investigação, outros espaços da comunidade tornaram-se espaços de pesquisa da Universidade do Estado da Bahia-UNEB: a escola Josafá Alves dos Santos foi um dos lugares que antecedeu a identificação do lócus da pesquisa: estudos feitos na comunidade anunciaram a existência de um leque epistemológico que envolve saberes, discursos e corpos.

Os sinais indicados pela presença feminina na escola, bem como o conhecimento da história e desenvolvimento da Comunidade de Saquinho abriram uma nova possibilidade de investigação, colocando em discussão e problematizando aspectos

\footnotetext{
${ }^{4}$ Esta pesquisa faz parte de um projeto macro intitulado Letramentos em Comunidades Rurais: Impactos Sociais na Família, Escola e Comunidade, desenvolvido pela Profa. Dra. Áurea da Silva Pereira. A partir do projeto macro foram realizados e desenvolvidos projetos de iniciação científica com base nos subsídios teóricos e metodológicos da pesquisa citada, além de projetos de extensão universitária que visam diálogos e trocas que beneficiam a comunidade.
} 
relacionados às questões de gênero e às relações de poder nelas existentes. Ademais, a discussão norteadora é sustentada pelos estudos dos letramentos e seus impactos na vida das mulheres em associação.

No percurso da pesquisa, buscou-se conhecer e analisar as práticas de letramentos produzidas pelas mulheres participantes da associação e discutir suas possíveis contribuições na atuação político-social das mulheres de Saquinho, assim como compreender de que forma o letramento contribui para o processo de ascensão social da mulher rural.

Apropriamo-nos dos aportes teóricos dos estudos de letramentos numa perspectiva política e ideológica, contemplada na malha teórica produzida por Brian Street (2015), Kleiman (2016) e Pereira (2014). E sobre gênero, buscamos subsídios nas teorias de Michele Perrot (2016) e Pierre Bordieu (2013). O corpo teórico foi revisitado à medida que fomos estabelecendo um diálogo com outras pesquisas sobre letramento e gênero. Desse modo, foi construída uma malha teórica para a construção da parte bibliográfica que fundamentou a pesquisa.

No decorrer da pesquisa de campo foi realizada a coleta de documentos escritos que integram a parte burocrática da associação, regem e autorizam seu funcionamento como instituição associativa, além de registros escritos informais, como cartazes, avisos e anotações. Fez-se com isso uma pesquisa documental, a qual se integrou como parte metodológica do trabalho.

O percurso metodológico delineou-se a partir da abordagem qualitativa, que permitiu abarcar ferramentas utilizadas em pesquisas educacionais e sociais, como observações, entrevistas narrativas e análise documental. Esta abordagem estuda fenômenos em contextos reais no seu acontecer natural. Partindo disso, os dados da pesquisa em Saquinho começaram a aparecer na estrada que leva até a comunidade; no caminho até os pontos de encontro com as colaboradoras; nas primeiras observações realizadas na pesquisa e em todos os atos performáticos dos moradores, assim como nos detalhes impressos na fotografia do lugar.

A organização local de Saquinho assemelha-se ao imaginário de cidades interioranas pequenas ou de comunidades rurais. Os mercadinhos, a igreja, a praça e as pessoas sentadas na frente das casas demostram a tranquilidade de uma vida simples e registram a comunidade em um primeiro olhar. Além disso, a presença da mulher em muitos lugares da comunidade e suas formas de estar nesses ambientes anunciam a 
configuração social de Saquinho com as mulheres protagonizando os movimentos sociais da localidade.

O propósito da narrativa autobiográfica de Dona Sônia, presidente da Associação das mulheres de Saquinho, era o de buscar pistas para conhecer os percursos de liderança e emancipação política, bem como os acontecimentos que demarcaram sua trajetória de vida até o ingresso na associação de mulheres. Embora a abertura da autobiografia permitisse que a narradora ampliasse fatos, relatasse detalhadamente muitos acontecimentos da sua vida, buscamos instigar sua formação pessoal a fim de saber o que demarcou sua relação com a comunidade, sua posição como líder comunitária e outros fatores pessoais e formativos da sua vida. Ao narrar-se, rememorando as experiências vividas, organizando fatos de sua vida e selecionando informações de forma conexas, Dona Sônia agia de forma autoral, biografizando a si mesma.

Este processo escrito ou oralizado pode ser considerado uma ferramenta de auto formação, pois os sujeitos podem retomar experiências passadas e, à medida que relembram fatos, refletem sobre seus percursos formativos e pessoais, construindo e formando a noção da sua própria identidade, a partir de compreensão de si mesmos.

As entrevistas narrativas com Dona Sônia foram realizadas em sua residência, e nada fugia à composição da sua própria narrativa: sua casa, os caminhos até ela e seus elementos físicos, seu quintal e as suas netas presentes neste cenário.

As rodas de conversas realizadas durante a pesquisa foram feitas, em sua maioria, no salão da igreja que hoje funciona como sede da associação. Nem sempre essas rodas contavam com todas as mulheres, pois as ocupações diárias impossibilitavam a participação destas. Ainda assim, em alguns encontros, essa proposta do contato de pesquisa foi adotada pela sua forma participativa, que produziu reflexões sobre os desafios do trabalho associativo e a compreensão do espaço em que vivem.

Além dos momentos de pesquisa a campo e das rodas de conversa, realizamos, junto à associação, eventos de formação e informação, caso da comemoração do Dia da Mulher. O evento, organizado de forma conjunta com as associadas, foi realizado na Escola Municipal Josafá Alves dos Santos e contou com a participação de militantes feministas, escritoras, enfermeiras e assistentes sociais que, juntas, concretizaram um momento de formação política, de troca de saberes e experiências. É importante 
destacar estes momentos, pois eles fizeram parte da trajetória de pesquisa e afirmaram um lugar de construção não centralizada em espaços de saber e poder, excluindo a possiblidade de debate único e construção epistemológica privilegiada por um feminismo acadêmico.

A pesquisa permitiu também conhecer as vivências e as representações que as participantes têm de suas experiências de vida; além disso, a apropriação desta abordagem considerou a reformulação de questões sobre a comunidade de Saquinho e sobre os letramentos da mulher do campo no próprio processo de pesquisa.

\section{Diálogo com os estudos de letramentos e de gênero}

Tomando como base os estudos de Brian Street $^{5}$ (2015) sobre os letramentos sociais é importante discutir as consequências reais do letramento para grupos e sociedades. Street (2015) assume uma perspectiva etnográfica, se distanciando do modelo autônomo de letramento para apreender a escrita na condição de práticas sociais plurais, ideológicas e culturais, revestidas de caráter local e específico. É nesta perspectiva que o conceito de letramento ideológico discute práticas de leitura e escrita socialmente construídas, atreladas a outros modos de conhecimento, saberes, identidades de ser e estar nas práticas sociais e em contextos particulares.

Street (2015) aponta para uma complexidade e dificuldades reais que os programas de alfabetização não abordam, restringindo-se apenas a levantamentos de números de "analfabetos", dificuldades nas habilidades de escrita e leitura e a questões sobre o acesso ao mercado de trabalho, mobilidade social e realização pessoal. Nesse sentido, o autor deixa pistas para compreensão de problemas muito mais complexos que precisam ser levados ao cerne das discussões sobre letramento e alfabetização.

Na perspectiva de Street (2015) sobre o tratamento dos problemas de letramento nas discussões políticas podemos perceber, através de alguns exemplos citados por ele, que existe uma noção equivocada sobre as avaliações de práticas letradas nos processos seletivos no mercado de trabalho. Nessas avaliações, os "níveis de letramento" não determinam a capacidade que o candidato tem para exercer as atividades exigidas em determinadas tarefas. Diferentemente disso, o nível escolar usado para medir o

\footnotetext{
${ }^{5}$ O livro foi publicado em inglês na década de 1990 e organizado originalmente em quatro seções. Na edição brasileira, foi traduzido por Marcos Bagno, organizado em cinco seções e teve sua primeira edição em 2014 pela Parábola Editorial.
} 
conhecimento da escrita se constitui como um critério de seleção e se revela como fator de exclusão que relaciona "capacidade letrada" com questões étnicas, raciais e de classe social. Ou seja, não se contrata uma pessoa se as suas habilidades letradas não forem suficientes para exercer a função determinada para o trabalho, mas utiliza-se esse tipo de letramento local como medidor de grupos minoritários e estigmatizados, os quais são excluídos pelos injustos critérios de seleção, cujos argumentos são relativos à falta de habilidades letradas.

As práticas sociais de determinados grupos devem ser analisadas a partir das suas funções e da própria concepção que os agentes de letramento lhes atribuem. No entanto, os programas de letramento, baseados em algumas concepções equivocadas, consideram esses grupos como analfabetos "passivos" e "atrasados". Essa concepção errônea está diretamente associada à teoria da "grande divisão", segundo Street (2015), em dois grupos: "letrados" e "iletrados".

Essa "grande divisão" tem sido responsável por estabelecer metas que definem os planos para o progresso econômico, alimentando uma preocupação que deixa escapar problemas reais e necessários os quais deveriam ser discutidos nos programas de letramento. Além disso, essa divisão entre "letrados" e "iletrados" provoca uma ideia que estigmatiza e rotula aqueles que não se encaixam nos grupos de "letrados" entrosados no poder dominante. Sobre essa afirmação, Street (2015) considera necessárias mudanças significativas nas concepções teóricas sobre o letramento. Uma dessas mudanças, de acordo com o autor, se refere à rejeição da teoria da "grande divisão" reformulando um debate público, o qual leve em conta as variedades de necessidades letradas.

Nessa mesma perspectiva, Kleiman e Sito (2016) discutem sobre o letramento ideológico e suas reflexões sobre as estratégias de letramento em grupos minoritários sustentam as questões levantadas nesta pesquisa sobre a função das práticas letradas da associação de mulheres de Saquinho como instrumento de emancipação. Neste sentido, Kleiman e Sito (2016, p. 177-178) afirmam:

\footnotetext{
${ }^{6}$ O termo "grande divisão" mencionado por Street se constitui em uma crítica aos trabalhos realizados por outros antropólogos que estudaram a escrita anteriormente, como o trabalho de ONG (1998). Ver a crítica de GEE (1984) a respeito.
} 
Os letramentos decorrentes de estratégias para lidar com grupos poderosos, na sociedade letrada, têm uma firme base na cultura oral, nas tradições musicais, no uso do espaço e do corpo, por meio dos quais são produzidos textos multimodais em que a linguagem oral e escrita ocupam papel secundário. Por isso, as escolhas metodológicas que assumimos, além de dialogar com os estudos decoloniais, utilizam um olhar antropológico para desvelar os letramentos dos sujeitos e compreender como eles tornam sua a escrita.

Os percursos teóricos das discussões de gênero foram iniciados com a leitura e reflexão das colocações de Bourdieu (2013) referentes aos processos de dominação masculina estendida a diferentes lugares e instituições onde as mulheres estão inseridas. A Associação das Mulheres Rurais da Comunidade de Saquinho e Região não escapa das forças simbólicas de dominação masculina como se pode observar em uma das partes da entrevista com Dona Sônia, presidente da associação dos produtores rurais, que depois menciona a criação da Associação das Mulheres de Saquinho; vejamos:

Depois da fundação da capela aqui na comunidade, a gente se reuniu para formar a primeira associação da comunidade, que foi a Associação Comunitária dos Produtores Rurais das Regiões de Saquinho e Gravatá, mas aí todo trabalho era feito pelas mulheres. A gente fazia rifa, arrecadava dinheiro. Em tudo as mulheres que fazia. Até a construção da estrada que liga Quizambu a Saquinho foi nós que correu atrás e conseguimos. Depois, a gente resolveu criar a associação só de mulheres. (D. Sônia - Entrevista narrativa).

O excerto textual revela traços de uma nova organização sexual do trabalho. Poderíamos chamar de trabalho que as mulheres assumem na comunidade, pois os homens se deslocam para fora da comunidade, onde encontram oportunidade de emprego, enquanto grande parte das mulheres atua dentro do espaço comunitário. Nesta organização, as mulheres tornam-se as principais protagonistas do desenvolvimento dos seus espaços de identidade, moldando e transformando seu território.

De acordo com Bourdieu (2013):

O efeito da dominação simbólica (quer ela seja de etnia, gênero, de cultura, de língua, etc.) não se produz na lógica pura das consciências cognoscentes, mas através de esquemas de percepção, de apreciação e de ação que são constitutivos do habitus e que sustentam, aquém das decisões da consciência e dos controles da vontade, uma relação de conhecimento que é profundamente obscura para si mesma. Deste modo, a lógica paradoxal da dominação masculina e da submissão feminina, de que se pode dizer, ao mesmo tempo e sem contradição, 
que é espontânea e extorquida, só se compreende se estivermos atentos aos efeitos duradouros exercidos pela ordem social sobre as mulheres (e sobre os homens), isto é, às disposições espontaneamente adaptadas à ordem que as impõe. (BOURDIEU, 2013, p. 54).

Esta concepção do esquema de dominação musculina serviu para compreender como as mulheres vão se organizando política e socialmente, construindo modos de liderança e resistência feminina mesmo com a saída dos homens para fora da comunidade em busca de emprego, enquanto elas realizam trabalhos dentro da comunidade. Nesta organização, as mulheres tornam-se as principais protagonistas do desenvolvimento dos seus espaços de identidade, moldando e transformando seu território. Entretanto, é bom atentar para o movimento dos homens e das mulheres. As mulheres criam seus espaços, mas são os homens que se deslocam para outras regiões em cidades mais próximas ou não, em busca de trabalho.

\section{A mulher rural e a inserção em espaços públicos}

A pesquisa mostra caminhos para compreender de que forma os letramentos produzidos na Associação das mulheres rurais de Saquinho - AMRS estão contribuindo para o empoderamento destas mulheres. A inserção e participação das mulheres nos espaços públicos e movimentos sociais em comunidades rurais patriarcais, como é o caso da comunidade da pesquisa, tem se constituído em dispositivo importante que demarca o lugar da mulher nos diversos encaminhamentos políticos e sociais da localidade. Além disso, constrói-se um legado histórico da mulher negra dentro das características de luta e militância.

A Associação de Mulheres de Rurais de Saquinho se constitui como uma agência de letramento e espaço de emancipação feminina. Ali as mulheres planejam e realizam seminários ou palestras sobre Doenças Sexualmente Transmissíveis - DST e cuidados com a saúde. Também organizam os eventos, movimentos sociais e festas culturais na comunidade. Ressaltamos que todos os acontecimentos sociais e cultuais são registrados em atas; a associação prepara convites, organiza o texto dos cartazes e encaminha para a gráfica produzir o material.

Observemos o registro de uma das atas, que mostra como as mulheres vão aprendendo a usar a escrita para os registros administrativos e orçamentários da associação: 
[...] Peguei 200 reais da associação para ajudar nas dispeza, como a divulgação do dia sete de março. Foi gasto sem reais. O outro sem foi para ajudar no restante das coisa do caruru e ajudar no arrastão das mulheres 2017. Foi falo também sobre o progeto do governo onde as mulheres decidirão ficar com a estufa e mudas de laranjas. No mês de março foi recadado 65 reais, não avendo nada mais a tratar encerrouse a assembleia onde lavrei a presente ata que foi assinada por $\operatorname{mim}[\ldots]^{7}$

O uso de termos técnicos, o esclarecimento de prestações de conta e outras habilidades registradas no uso da escrita mesclam-se com traços particulares de nível de escolaridade da secretária da associação, eleita pelas mulheres para assumir o papel de escriba. Embora a escrita da ata não esteja totalmente de acordo com as regras padronizadas e estabelecidas em termos linguísticos pelas instituições que regularizam o uso de uma língua oficial, todo o conteúdo presente neste documento atende, de forma satisfatória, o seu objetivo. As decisões tomadas em reunião são registradas, formalizadas e divulgadas através da ata.

Os registros da ata mostram que as participantes da AMRS se apropriam daquilo que é necessário para manter a interação com instituições que exigem formas padronizadas de escrita, embora não descartem traços e formas da prática letrada do cotidiano familiar e comunitário na escrita de documentos oficiais.

Esta relação intercultural de diferentes letramentos e a homogeneização exigida pelas agências oficiais para o cumprimento da interação entre os sujeitos sociais, ressignifica as práticas letradas das mulheres associadas, as quais já percebem essa apropriação como instrumento de poder e emancipação, embora esse processo esteja permeado por fatores de exclusão que se manifestam através do uso da língua.

O estatuto da Associação de Mulheres Rurais de Saquinho e Região compõe o acervo de documentos e registros necessários para o funcionamento do grupo. A estrutura deste estatuto mostra a sustentação do movimento enquanto organização local e efetiva, pois o documento rege o funcionamento do grupo, os objetivos, a composição dos cargos, suas competências e disposições gerais. Diante dessa composição, em uma análise mais geral do estatuto da associação, percebe-se a intenção de um processo de

\footnotetext{
${ }^{7}$ Transcrição da Ata da Associação de Mulheres Rurais de Saquinho e Região do dia 05 de março de 2017. Mantida a grafia original.
} 
transformação coletiva, de aprendizado da cidadania e de elaborações de ações que podem efetivamente transformar a vida em comunidade.

Diante disso, podemos pensar na necessidade de um movimento de mulheres integrado e multidisciplinar, referente à formação política, que compreenda as demandas da pluralidade desses movimentos. Assim sendo, a Associação de Mulheres Rurais de Saquinho se constitui como um movimento emancipatório. É um espaço de aprendizado e formação que integra de forma institucional a agenda das mulheres rurais de Saquinho.

Não podemos fugir da história social e cultural da mulher do campo para pensar as trajetórias de construções sociais nas quais estiveram e estão inseridas. Michelle Perrot (2016) na obra Minha história das mulheres, traça o percurso das mulheres em diferentes abordagens e tempos históricos sociais e culturais. Uma dessas breves análises está relacionada à mulher do campo, sinalizando as mudanças que ocorreram neste espaço:

Por muito tempo, aparentemente imóvel, a vida nos campos muda, e a das mulheres também. Por influência do mercado e das comunicações. Pela industrialização. Pelo êxodo rural. Pelas ações das guerras, principalmente a de 1914-1918, que escravizou o campo de seus jovens e transferiu uma parte de suas tarefas e de seus poderes para as mulheres: elas aprenderam a lavrar a terra, gesto viril, e a gerenciar seu negócio. (PERROT, 2016, p. 113).

Longe da tentativa de generalizar todas as mulheres dentro dessas mudanças sociais, podemos concordar com a percepção de Perrot (2016) quando associamos o movimento das populações rurais para a cidade com as consequentes e novas atribuições relacionadas às mulheres do campo. Tais mudanças já começam a acentuar as diferenças entre essas mulheres. A mulher do campo começa a assumir outras tarefas e atividades, enquanto liderança familiar. Essa característica de liderança vai, aos poucos, rompendo os muros domésticos e familiares, tomando a comunidade e o âmbito público. É neste sentido que podemos visualizar o geminar da luta das mulheres rurais através da criação de associações.

A criação e funcionamento desses espaços de associações comunitárias rurais e a liderança feminina frente a esses movimentos revelam o domínio social, econômico e cultural da mulher sobre determinadas atividades (AMORIN, 1997). Isso desfaz a ideia estereotipada e generalizada do imaginário sobre a mulher rural que, como constatado, 
lida com o trabalho pesado do campo, embora ainda persista o estereótipo da passividade e subserviência dessa mulher, submetida às imposições de uma comunidade tradicional e patriarcal. Ainda é possível identificar fortes marcas dessa cultura da hegemonia masculina, apesar de haver espaços rurais nos quais já se identifica, de forma latente, a presença atuante e transformadora da mulher em luta.

Pereira (2014) descreve a sua primeira impressão sobre a participação das mulheres nos espaços da comunidade focalizada na sua pesquisa de doutoramento:

Percebi nas diversas cenas que compõem o cotidiano de Saquinho que são as mulheres que lideram e participam dos diferentes espaços da comunidade. Após o contato inicial, fiz duas visitas aos espaços do TOPA $^{8}$, em outubro de 2010, com o objetivo de conhecer os frequentadores e percebi que, além de ser maioria, a mulher fazia a diferença naqueles espaços pela assiduidade e participação. (PEREIRA, 2014, p.30).

Esta constatação reafirma as novas configurações sociais entre gênero e espaço. A mulher não mais se restringe ao confinamento doméstico por conta de um processo histórico de exclusão, violência, silenciamento e desconsideração dos seus saberes e da sua posição e começa a investir em seus espaços - escola, trabalho, movimentos sociais - e nas suas potencialidades.

Na pesquisa de Pereira (2014), o retrato da mulher de Saquinho reafirma a crescente inserção dessas mulheres nos espaços onde poderiam encontrar mais possibilidades de visibilidade e independência. Assim, Pereira (2014, p.82) descreve:

$\mathrm{Na}$ trajetória da pesquisa, observamos que, apesar da idade, essas mulheres, após cuidar do marido, dos filhos, dos netos, da lavoura, da cozinha, ainda encontram energia e motivação para ingressar na sala de aula em busca de novas aprendizagens, conhecimentos e empoderamento; no desejo de se posicionar socialmente, de assumir sua cidadania por meio do ato de estudar, de aprender a ler e a escrever. Nota-se, também, outra realização evidenciada nas suas falas: a afirmação de independência perante o marido, os filhos e a comunidade, a expansão do seu universo para além das fronteiras do casamento.

Para além de uma formação doméstica, as mulheres de Saquinho têm suas vidas alteradas e influenciadas na interação com instituições como a escola, a igreja e associações. Na busca de formação, as mulheres norteiam novos rumos em suas

\footnotetext{
${ }^{8}$ TOPA - Programa de Alfabetização para Todos, implantado em 2007 no estado da Bahia.
} 
histórias por meio de mudanças no modelo familiar tradicional e no próprio seio da comunidade. Embora passem muito tempo no campo trabalhando, há uma mobilização frequente destas mulheres ao organizar mutirões, assembleias, reuniões de associações. Estes agrupamentos tornam-se modos de articulação entre elas à medida que há troca de saberes, de experiências tanto na vida no campo, quanto na vida privada. É notável que a decisão consciente e prática na iniciativa de criar e agrupar mulheres num mesmo espaço com intuito de dividir experiências, de desenvolver alternativas diante das dificuldades e, sobretudo, de aliviar tensões, comporte uma mulher ainda caseira e preocupada com a família, mas engajada e fortalecida.

A participação política dos movimentos de mulheres rurais vem contribuindo para o seu reconhecimento como sujeito de direito. Esta afirmativa é corroborada por Aguiar (2016) em seu estudo sobre a atuação do movimento de mulheres rurais a partir das reflexões sobre a Marcha das Margaridas ${ }^{9}$, movimento coletivo protagonizado por mulheres do campo e da floresta, que ocorre a cada quatro anos em Brasília-DF. A Marcha das Margaridas abrange uma dimensão não apenas simbólica, mas atuante e política nas reivindicações e criação de projetos cobrados ao poder público.

Os movimentos sociais têm ganhado notoriedade nos últimos anos. Esta cultura política vem sendo ampliada nos mais diferentes âmbitos sociais - ocupações escolares, grupos feministas, movimentos partidários, movimento negro, e LGBT, entre outros. Cada um desses movimentos imprime particularidades, pautas diferenciadas e modos de organização heterogêneos. Dentro desses modos de organização, estão os agenciamentos organizados por diferentes formas de conduzir ações e debates.

A partir das discussões sobre as particularidades de cada movimento, especificamente do movimento de mulheres rurais, torna-se pertinente analisar como as práticas letradas têm sido utilizadas para atividades de ações, discussões e projetos dentro da associação de Mulheres Rurais de Saquinho e Região. Para isso, é preciso buscar uma compreensão dos fenômenos letrados em estudos sobre letramentos.

O conceito de letramentos emergentes, discutido por Kleiman e Sito (2016, p. 175) definido como "recriações de gêneros secundários, tomando para si, ainda, objetos

\footnotetext{
${ }^{9}$ A Marcha das Margaridas é uma ação estratégica das mulheres do campo e da floresta que integra a agenda permanente do Movimento Sindical de Trabalhadores e Trabalhadoras Rurais (MSTTR) e de movimentos feministas e de mulheres. A Marcha acontece em Brasília-DF de quatro em quatro anos, mas mantém pautas e ações permanentes através de uma agenda que reivindica igualdade, liberdade, acesso à terra, fim da violência contra a mulher, entre outras demandas.
} 
e artefatos do "outro" majoritário para fazer emergir e para fortalecer as múltiplas práticas letradas que lhes são necessárias para interagir com e nas instituições contemporâneas", aponta para a real necessidade de conhecer práticas de letramento mais distanciadas, das experiências letradas de grupos minoritários. Isso porque, em um contexto de interação com as práticas letradas institucionalizadas ocorrerá a exigência daquelas habilidades letradas legitimadas nas situações de interação entre grupos com desigual acesso à escrita. Dessa forma, levando em conta as desigualdades de toda ordem entre as instruções linguísticas de um grupo minoritário e as de um grupo hegemônico, caberia compreender como as comunidades marginalizadas lidam com essas escritas e leituras e quais são suas estratégias.

Neste sentido, poderíamos pensar que as comunidades rurais e suas práticas letradas não apenas devem afirmar suas particularidades de identidade linguística, mas também se apropriar do letramento "do outro", ressignificando algumas formas e estabelecendo meios para manter uma relação mais igualitária com os meios de acesso ao poder e aos direitos que ainda precisam ser reivindicados.

Os letramentos decorrentes de estratégias para lidar com grupos poderosos, na sociedade letrada têm, como já dito, firme base na cultura oral, nas tradições musicais, no uso do espaço e do corpo por meio dos quais são produzidos textos multimodais em que a linguagem oral escrita ocupa papel secundário (KLEIMAN; SITO, 2016). A ideia de domínio de práticas letradas para interação social e para emancipação da mulher em associação comunitária é perpassada pelo entendimento de que elas têm marcas identitárias e devem ser enxergadas como práticas libertadoras. E, em certa medida, essas práticas criadas e utilizadas na associação atendem aos seus objetivos enquanto ferramenta política, pois através delas a manutenção do grupo é garantida.

A Associação de Mulheres Rurais de Saquinho e Região dispõe de documentos jurídicos e formais como estatuto, atas, requerimentos, cadastros de inscrição federal, entre outros. Isso revela que a associação busca um engajamento com os dispositivos institucionais exigidos para participação plena das políticas públicas de governo. Este mecanismo em prol do estabelecimento oficial do grupo pode ser percebido na estrutura do estatuto da associação e mostra a sustentação do movimento enquanto organização local e efetiva, pois o documento, conforme já comentado, rege o funcionamento do grupo, os objetivos, a composição dos cargos, suas competências e disposições gerais. 
As participantes da AMRSR se apropriam daquilo que é necessário para manter a interação com instituições que exigem formas padronizadas de escrita, embora não descartem traços e formas da prática letrada do cotidiano familiar e comunitário na escrita de documentos oficiais.

A partir dos objetivos descritos no estatuto da associação, podemos perceber que o grupo contempla uma agenda ampla e ao mesmo tempo específica para a mulher do campo. No entanto, essa especificidade ainda não abrange uma pauta que contemple a luta feminista, pois, no estatuto da própria associação, não há pressupostos nem princípios de uma política mais abrangente para as mulheres, principalmente para as mulheres negras, que compreendem o grupo de maior vulnerabilidade e ainda permanecem na base da pirâmide social.

Não faz sentido pensar em políticas e estratégias de desenvolvimento social sem garantir, em primeiro lugar, o direito fundamental da mulher de viver sem violência, seja ela de qualquer forma ou tipologia: física, sexual, psicológica, institucional. E no contexto do campo ainda existem várias situações completamente desfavoráveis às mulheres rurais quando estas decidem denunciar a violência. Reflexo, primeiramente, de uma engrenagem patriarcal iniciada na própria formação familiar que situa a mulher em uma condição subserviente e, por isso, passiva às situações de violência; resultado, em segundo lugar, da ineficiência das políticas públicas de apoio à mulher, geradas e instituídas de uma forma centralizada nas metrópoles e cidades, deixando de lado as comunidades rurais que fazem parte da demarcação territorial urbana, como é o caso de Saquinho em relação à cidade de Inhambupe.

A análise de atas e documentos para concorrer a projetos de subsídios do governo mostra que as práticas de letramento são ferramentas necessárias para as atividades da associação e, em função disso, surgem como mecanismo de poder que interfere e modifica a relação das mulheres no seu espaço social de forma geral.

Percebe-se diante da análise dos documentos da associação, que parte dessas mulheres tem certa instrução compreendendo aí, a leitura, a escrita, bem como os saberes e experiências vivenciais, como já discutido anteriormente.

Sendo assim, podemos questionar os impactos da hegemonia patriarcal na Comunidade de Saquinho, que, embora seja cenário de um forte protagonismo feminino, ainda inclina-se para uma interferência masculina nas atividades que 
poderiam ser exercidas por mulheres, garantindo a autonomia e a plena participação nas decisões, ações, atividades e desenvolvimento dos seus espaços.

É sob tal aspecto que a reflexão feita a partir dessa lógica pode estabelecer relações entre os letramentos sociais como atributos necessários para a emancipação da mulher, pois as práticas letradas podem ser potencializadas para a formação política, desenvolvendo habilidades de escrita, discursivas e de cunho formal $\mathrm{e}$ institucionalizado. Sendo assim, percebemos a possibilidade de sinais de ascensão e emancipação das associadas, enquanto mulheres que utilizam as práticas letradas possíveis nas atividades do grupo. É neste sentido que visualizaremos a formação de mulheres em condição de vulnerabilidade social, através da ampliação e desenvolvimento das habilidades letradas.

\section{Considerações finais}

As discussões iniciadas neste trabalho complementam a percepção da língua como instrumento de poder. As armas e estratégias produzidas por este instrumento potencializam a luta da mulher negra e rural que carrega historicamente um legado de resistência.

Percebemos, na trajetória da pesquisa, que os saberes letrados se constituem como a base de interação entre elas no funcionamento da associação, bem como entre outras instituições acionadas para ouvir suas demandas e garantir o cumprimento das suas reivindicações.

Os letramentos utilizados pelas associadas se revelam como saberes necessários para a liderança no movimento de mulheres rurais. E por esta perspectiva coube nesta pesquisa uma ampliação da discussão de letramento. Esta compreensão se deu a partir na narrativa da presidenta da associação, nas rodas de conversa com as mulheres e nos registros das atividades culturais e sociais realizados pela AMSR. Consideramos que a narrativa de D. Sônia revela experiências adquiridas no processo de migração de um estado para outro: a experiência de uma mulher negra que sai do interior da Bahia para trabalhar como empregada doméstica.

Todos esses saberes são considerados como saberes letrados que contribuíram para o trabalho da presidenta em questão. Outros saberes vivenciais e vindos da experiência das outras mulheres de Saquinho também são fatores de emancipação que 
precisam ser estudados e refletidos para a identificação das potencialidades de cada uma dessas mulheres que já iniciam uma luta pela busca de dignidade, equidade de gênero e justiça social.

Para que os resultados desta pesquisa tenham de fato uma aplicabilidade direta ao grupo pesquisado em questão é preciso pensar em um passo a mais. Para isso, as discussões e resultado parciais desse trabalho não descartam o modo cooperativo e participativo na relação pesquisador(a)/pesquisado(a) e lançam a ideia de uma pesquisaação, ação esta pensada no processo de investigação, que buscará orientar e discutir possibilidades de ampliação das práticas letradas burocráticas e institucionalizadas para usá-las como ferramenta a favor da emancipação pelo trabalho comunitário liderado por mulheres.

Esta pesquisa revelou-se como uma ferramenta para as discussões de gênero, ruralidade e letramento à medida que forneceu subsídios para a malha teórica que compreende a mulher dentro de um quadro de atuação social que busca a emancipação feminina nas instâncias de poder. Diante disso, as (in)conclusões desta pesquisa podem ser fomentos para estabelecer uma luta integrada entre mulheres na sua pluralidade, além de impulsionar projetos de contribuição social que deem visibilidade aos movimentos de mulheres rurais, levando em conta os letramentos como ferramentas essenciais a essa formação política.

\section{Referências bibliográficas}

AGUIAR, Vilenia Venancio Porto. Mulheres rurais, movimento social e participação: reflexões a partir da Marcha das Margaridas. Política e Sociedade: revista de sociologia política. V.15. 2016.

AMORIM, Maria Joana P. Espaços femininos: gênero, identidade em comunidades rurais na Amazônia. In: ALVARES, Maria Luzia M.; SANTOS, Eunice F. dos. (Orgs.). Desafios de identidade: Espaço-tempo de mulher. Belém: CEJUP:GEPEM:REDOR, 1997.

BOURDIEU, Pierre. A dominação masculina. Lisboa: Relógio D Água editores, 2013 DAVIS, Ângela. Mulheres, raça e classe. Tradução Heci Regina Candiani. 1 ed. São Paulo: Bomtempo, 2013.

GEE, James P. Oralidade e alfabetização: Da Mente Selvagem aos Caminhos com Palavras. TESOL 20, 4, 1986. 
ONG, Walter. Oralidade e cultura escrita: a tecnologização da palavra. Campinas, SP: Papirus, 1998.

PEREIRA, Áurea da Silva. Tempo de plantar, tempo de colher: mulheres idosas, saberes de si e aprendizagens de letramento em Saquinho. Tese. Doutorado em Educação e Contemporaneidade. Salvador: Universidade do Estado da Bahia, 2014.

PERROT. Michelle. Minha história da mulheres. São Paulo: Contexto, 2016.

KLEIMAN, Ângela B; SITO, Luanda Rejane Soares. Multiletramentos, interdições e marginalidades. In: KLEIMAN, Ângela B.; ASSIS, Juliana Alves. (Orgs.) Significados e ressignificações do letramento: desdobramentos de uma perspectiva sociocultural sobre a escrita. Campinas (SP): Mercado de Letras, 2016.

STREET, Brian. Letramentos Sociais: abordagens críticas do letramento no desenvolvimento, na etnografia e na educação. Tradução Marcos Bagno. São Paulo: Parábola editorial, 2015. 